\title{
Electronic and Thermal Transport Properties of Complex Structured Cu-Bi-Se Thermoelectric Compound with Low Lattice Thermal Conductivity
}

\author{
Jae-Yeol Hwang, ${ }^{1}$ Hyeona Mun, ${ }^{2}$ Jung Young Cho, ${ }^{3}$ Sang Sun Yang, \\ Kyu Hyoung Lee, ${ }^{3}$ and Sung Wng Kim ${ }^{1,2}$ \\ ${ }^{1}$ Center for Integrated Nanostructure Physics, Institute for Basic Science (IBS), Daejeon 305-701, Republic of Korea \\ ${ }^{2}$ Department of Energy Science, Department of Physics, Sungkyunkwan University, Suwon 440-746, Republic of Korea \\ ${ }^{3}$ Materials R\&D Center, Samsung Advanced Institute of Technology, Samsung Electronics, Yongin 446-712, Republic of Korea \\ ${ }^{4}$ Powder and Ceramics Division, Powder Technology Department, Korea Institute of Materials Science, \\ Changwon 642-831, Republic of Korea
}

Correspondence should be addressed to Kyu Hyoung Lee; kyuhyoung.lee@samsung.com

and Sung Wng Kim; kimsungwng@skku.edu

Received 22 June 2013; Revised 20 July 2013; Accepted 5 August 2013

Academic Editor: Hyung-Ho Park

Copyright (C) 2013 Jae-Yeol Hwang et al. This is an open access article distributed under the Creative Commons Attribution License, which permits unrestricted use, distribution, and reproduction in any medium, provided the original work is properly cited.

\begin{abstract}
Monoclinic $\mathrm{Cu}_{x+y} \mathrm{Bi}_{5-y} \mathrm{Se}_{8}$ structure has multiple disorders, such as randomly distributed substitutional and interstitial disorders by $\mathrm{Cu}$ as well as asymmetrical disorders by Se. Herein, we report the correlation of electronic and thermal properties with the structural complexities of $\mathrm{Cu}_{x+y} \mathrm{Bi}_{5-y} \mathrm{Se}_{8}$. It is found that the interstitial $\mathrm{Cu}$ site plays an important role not only to increase the electrical conductivity due to the generation of electron carriers but also to reduce the thermal conductivity mainly due to the phonon scattering by mass fluctuation. With impurity doping at the interstitial $\mathrm{Cu}$ site, an extremely low lattice thermal conductivity of $0.32 \mathrm{~W} \cdot \mathrm{m}^{-1} \cdot \mathrm{K}^{-1}$ was achieved at $560 \mathrm{~K}$. These synergetic effects result in the enhanced dimensionless figure of merit $(Z T)$.
\end{abstract}

\section{Introduction}

In thermoelectric (TE) materials, thermal energy is directly converted into electrical energy and vice versa through the flow of charge carriers (electrons or holes) in solid state without any moving parts $[1,2]$. The performance of TE device depends on the temperature gradient $(\Delta T)$ and the dimensionless figure of merit $(Z T)$ in TE material. The conversion efficiency of TE material is governed by $Z T$, which is defined as $Z T=S^{2} \cdot \sigma \cdot T / \kappa$, where $S$ is the thermopower (Seebeck coefficient), $\sigma$ is the electrical conductivity, $\kappa$ is the thermal conductivity, and $T$ is the absolute temperature. Intuitively, good TE materials should have sufficiently large $S$, high $\sigma$, and low $\kappa$. Based on this relation, there are two different kinds of straightforward strategies for achieving high ZT. The first one is maximizing power factor $\left(\mathrm{PF}=S^{2} \cdot \sigma\right)$ by the modification of the electronic states through the optimization of doping, introduction of nanoscale materials, and so forth. The other one is minimizing $\kappa$ by the perturbation of structural arrangements for enhancing phonon scattering through solid-solution alloying [3-6], nanostructuring [7, 8], and the development of new materials with intrinsically low $\kappa$. However, since $\sigma, S$, and $\kappa$ are the functions of charge carriers as well as these physical parameters are intercorrelated to each other, it is very difficult to control these parameters individually. Recent TE researches have been mainly focused on breaking the trade-off relationship between $\sigma$ and $\kappa$ by reducing the lattice thermal conductivity $\left(\kappa_{\text {latt }}\right)$ due to the relative easiness of reducing $\kappa_{\text {latt }}$ without considerably affecting other electronic transport parameters ( $S$ and $\sigma$ ). Thus, extensive researches have been focused on reducing $\kappa_{\text {latt }}$ by utilizing nanostructures and compositional inhomogeneities of state-of-the-art TE materials such as $\mathrm{Bi}_{2} \mathrm{Te}_{3}, \mathrm{PbTe}$, and $\mathrm{SiGe}$ [3-8]. It has been reported that dramatically reduced $\kappa_{\text {latt }}$ in TE materials is due to one of 
the following mechanisms: alloy scattering [3-6], resonant scattering [9-13], anharmonic scattering [14], and interface scattering of phonons [15-17] or their combination.

Recently, much effort has been focused on discovering new semiconducting materials with intrinsically low $\kappa_{\text {latt }}$. Such materials have a solid potential compared to conventional TE materials because their $\kappa_{\text {latt }}$ can be further reduced by compositional and microstructural engineering without sacrificing the other electronic properties. The common structural characteristics of low $\kappa_{\text {latt }}$ materials are complex structures, which have relatively large unit cells, sublattice disorders, low crystal symmetry, and/or a variety of atom types combined with random distributions. These result in the effective phonon scatterings, which make these materials promising candidates for TE applications.

By understanding the origin of low $\kappa$ in complex structured system, it is possible to find a clue for novel TE materials with an appropriate structure and to manipulate structural arrangement for the achievement of low $\kappa$ in conventional TE materials. In a previous article [18], we reported new TE materials, which are the pavonite homologues $\mathrm{Cu}_{x+y} \mathrm{Bi}_{5-y} \mathrm{Se}_{8}$ $(1.2 \leq x \leq 1.5,0.1 \leq y \leq 0.4)$ with low $\kappa_{\text {latt }}\left(0.41-0.55 \mathrm{~W} \cdot \mathrm{m}^{-1} \cdot \mathrm{K}^{-1}\right.$ at $300 \mathrm{~K}$ ) owing to the structural complexity. In the present study, we investigated the electronic and thermal transport properties in the view point of the correlation with crystal structure in order to clarify the origin of TE properties in the homologous $\mathrm{Cu}_{x+y} \mathrm{Bi}_{5-y} \mathrm{Se}_{8}$ compounds.

\section{Experimental}

Crystal ingots of $\mathrm{Cu}_{x+y} \mathrm{Bi}_{5-y} \mathrm{Se}_{8}$ compounds were fabricated by conventional melting technique by the use of highpurity elemental $\mathrm{Cu}$ (99.999\%, CERAC), Bi (99.999\%, 5N Plus), and Se (99.9\%, 5N Plus) as starting materials. The stoichiometric mixtures of the elements were loaded into a quartz tube of $14 \mathrm{~mm}$ in diameter. The tube was vacuumsealed and the mixed contents were melted in a furnace for $10 \mathrm{hrs}$ at $1273 \mathrm{~K}$; then, they were water quenched. The ingots were ground using ball mill, and compacted bulk samples of $10 \mathrm{~mm}$ in diameter and $13 \mathrm{~mm}$ in thickness were prepared using spark plasma sintering (SPS) technique under dynamic vacuum and with the application of $50 \mathrm{MPa}$ of uniaxial pressure at $663 \mathrm{~K}$. The relative densities of the resulting consolidated samples were found to range from 7.22 to $7.48 \mathrm{~g} \cdot \mathrm{cm}^{-3}$, which are more than $95 \%$ of the theoretical value. We used $\mathrm{Cu}_{1.7} \mathrm{Bi}_{4.7} \mathrm{Se}_{8}\left(\mathrm{Cu}_{x+y} \mathrm{Bi}_{5-y} \mathrm{Se}_{8}, x=1.4, y=\right.$ 0.3 ) as a reference material, and small amount ( $w$ and $z=$ 0.0085 and 0.025 for the interstitial and substitutional $\mathrm{M}$ sites, resp.) of $\mathrm{Zn}$ or In was introduced in host $\mathrm{Cu}_{1.7-w} \mathrm{M}_{w} \mathrm{Bi}_{4.7} \mathrm{Se}_{8}$ or $\mathrm{Cu}_{1.7} \mathrm{Bi}_{4.7-z} \mathrm{M}_{z} \mathrm{Se}_{8}$ matrix to elucidate the electronic and thermal properties according to the different carrier concentrations. The electronic transport properties including $\sigma$ and $S$ were measured from $300 \mathrm{~K}$ to $560 \mathrm{~K}$ using an ULVAC ZEM-3 system. The $\kappa$ values $\left(\kappa=\rho_{s} \cdot C_{p} \cdot \lambda\right)$ were calculated from measurements taken separately: sample density $\left(\rho_{s}\right)$, heat capacity $\left(C_{p}\right)$, and thermal diffusivity $(\lambda)$ measured under vacuum by laser-flash method (TC-9000, ULVAC, Japan), in which $C_{p}$ was used as the constant value

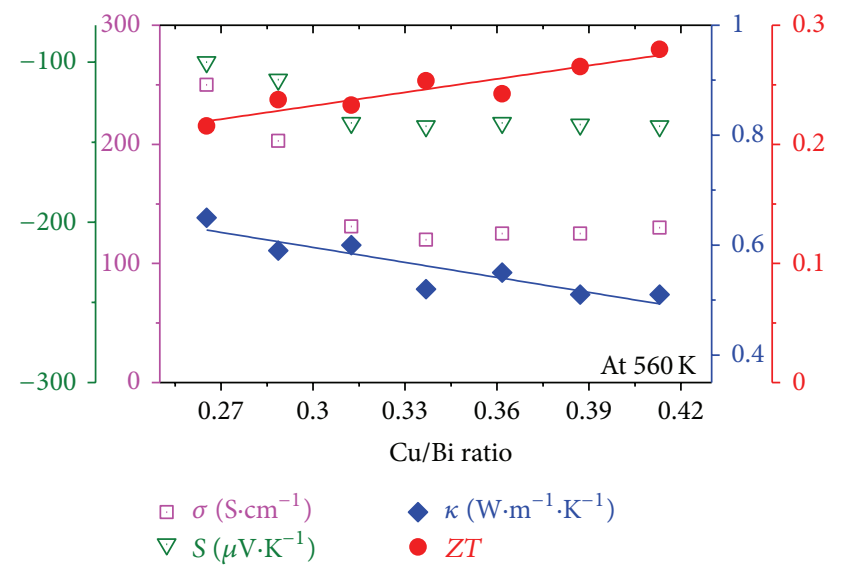

Figure 1: Electrical conductivity $(\sigma)$, Seebeck coefficient $(S)$, thermal conductivity $(\kappa)$, and $Z T$ as functions of $\mathrm{Cu} / \mathrm{Bi}$ ratio in $\mathrm{Cu}_{x+y} \mathrm{Bi}_{5-y} \mathrm{Se}_{8}(1.2 \leq x \leq 1.5,0.1 \leq y \leq 0.4)$ pavonite homologues. All data were acquired at $560 \mathrm{~K}$.

of $0.225 \mathrm{~J} \cdot \mathrm{g}^{-1} \cdot \mathrm{K}^{-1}$ estimated from the Dulong-Petit fitting using low temperature $C_{p}$ data. All measured data, which were acquired at the same dimension and configuration, are obtained within the experimental error of about $5 \%$.

\section{Results and Discussions}

Figure 1 shows $\mathrm{TE}$ properties for the homologous $\mathrm{Cu}_{x+y} \mathrm{Bi}_{5-y} \mathrm{Se}_{8}(1.2 \leq x \leq 1.5,0.1 \leq y \leq 0.4)$ system at $560 \mathrm{~K}$ with varying compositional ratio between $\mathrm{Cu}$ and $\mathrm{Bi}$. The absolute value of $S$ decreases linearly with increasing $\sigma$, indicating that the semiconducting transport properties do not significantly change with varying the $\mathrm{Cu} / \mathrm{Bi}$ ratio. Based on theoretical calculations of the previous report, interstitial $\mathrm{Cu}$ is regarded as the main source of electron carriers in the $\mathrm{Cu}_{x+y} \mathrm{Bi}_{5-y} \mathrm{Se}_{8}$ system [18]. Because the electron distributions around interstitial $\mathrm{Cu}$ ions, which are shown in the crystal structure of $\mathrm{Cu}-\mathrm{Bi}-\mathrm{Se}$ pavonite compound (Figure 2(a)), overlapped each other along $b$-axis, the degree of overlapping depends on the content of the interstitial $\mathrm{Cu}$. This might be a possible reason for the changes in electrical properties by perturbing $\mathrm{Cu}$ sites, since the interstitial $\mathrm{Cu}$ sites locate along $b$-axis and work as an electrical conduction path, leading to an improvement of electron transfer across the basal plane. On the other hand, $\kappa$ decreases from 0.65 to $0.51 \mathrm{~W} \cdot \mathrm{m}^{-1} \cdot \mathrm{K}^{-1}$ by increasing $\mathrm{Cu}$ content. The highest $Z T$ value of 0.27 at $560 \mathrm{~K}$ was obtained in the $\mathrm{Cu}_{1.9} \mathrm{Bi}_{4.6} \mathrm{Se}_{8}$ composition, which has the highest $\mathrm{Cu}$ concentration among samples, mainly due to its low $\kappa$. Thus, it is suggested that statistically distributed interstitial $\mathrm{Cu}$ along $b$-axis may be the main factor affecting the electronic (by generating electron carriers) and thermal transport (by enhancing phonon scattering) properties in this system. In order to understand the TE transport behavior based on the roles of the interstitial $\mathrm{Cu}$ and substitutional Bi sites, we individually modified those sites by impurity doping.

$\mathrm{Cu}_{1.7} \mathrm{Bi}_{4.7} \mathrm{Se}_{8}$ was chosen as a base composition for doping, since this composition showed stable structure 


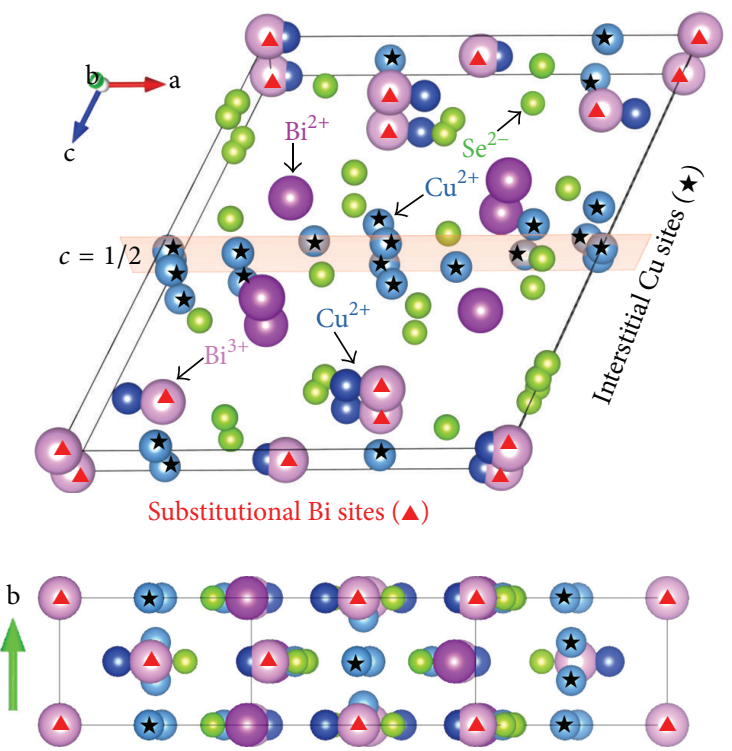

(a)

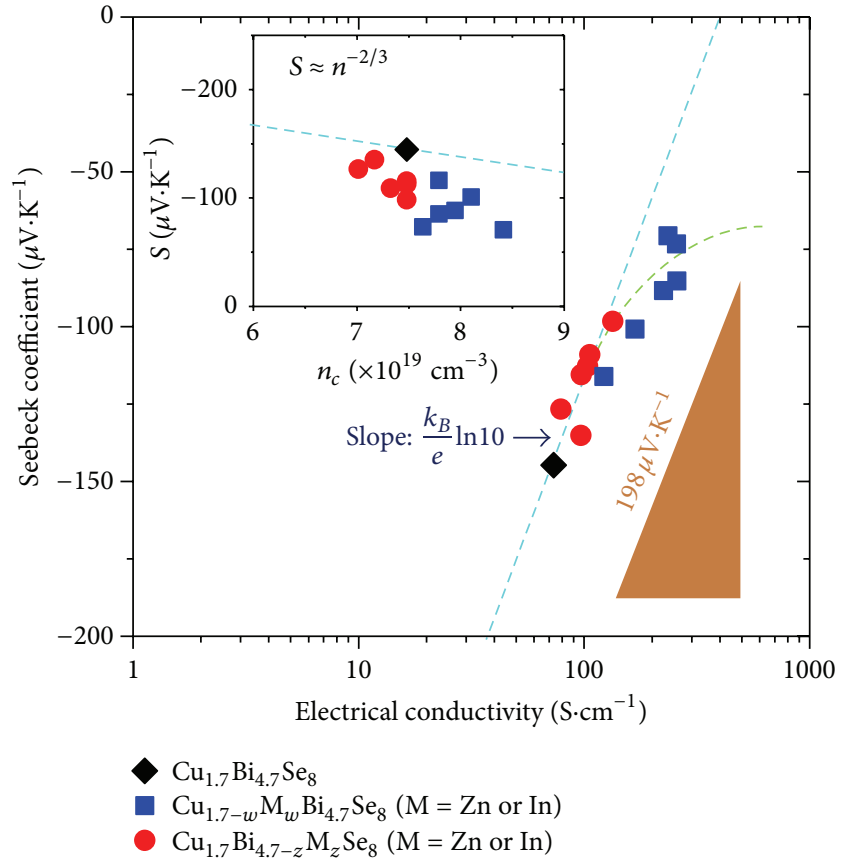

(b)

Figure 2: (a) Crystal structure of $\mathrm{Cu}_{1.7} \mathrm{Bi}_{4.7} \mathrm{Se}_{8}$ with interstitial $\mathrm{Cu}$ and substitutional Bi sites. (b) Seebeck coefficient as a function of electrical conductivity $(\sigma)$ for $\mathrm{Cu}$-Bi-Se system. Blue and red dots indicate $\mathrm{Cu}_{1.7-w} \mathrm{M}_{w} \mathrm{Bi}_{4.7} \mathrm{Se}_{8}$ and $\mathrm{Cu}_{1.7} \mathrm{Bi}_{4.7-z} \mathrm{M}_{z} \mathrm{Se}_{8}$ systems, respectively. Black dot is a base $\mathrm{Cu}_{1.7} \mathrm{Bi}_{4.7} \mathrm{Se}_{8}$ compound. The inset is Pisarenko plot at $300 \mathrm{~K}$, representing the Seebeck coefficient $(S)$ as a function of carrier concentration $\left(n_{c}\right)$. The dashed line corresponds to the theoretically expected curve for $\mathrm{Cu}_{1.7} \mathrm{Bi}_{4.7} \mathrm{Se}_{8}$ with effective mass of $m^{*} \sim 0.21 m_{0}$.

and reproducible physical properties. Figure 2(b) shows the Jonker plot of $\mathrm{Cu}$-Bi-Se system. Most of the experimental data points for $\mathrm{Cu}_{1.7} \mathrm{Bi}_{4.7-z} \mathrm{M}_{z} \mathrm{Se}_{8}$ compounds lie on the straight line (cyan dashed) with the slope of $198 \mu \mathrm{V} \cdot \mathrm{K}^{-1}$. However, in case of the interstitial $\mathrm{Cu}$ site modified $\mathrm{Cu}_{1.7-w} \mathrm{M}_{w} \mathrm{Bi}_{4.7} \mathrm{Se}_{8}$ compounds, the slope (green dashed line) was changed in the region of largely increased $\sigma$ (Figure 2(b)), indicating that the electronic state was altered to a highly degenerate state by doping at the interstitial $\mathrm{Cu}$ sites. In Pisarenko plot (the inset of Figure 2(b)), all data points lie below the theoretically expected Pisarenko curve (cyan) for undoped $\mathrm{Cu}_{1.7} \mathrm{Bi}_{4.7} \mathrm{Se}_{8}$ with effective mass of $m^{*}\left(\sim 0.21 m_{0}\right)$. These electronic transport properties might be related to the changes in the Hall mobility $\left(\mu_{H}\right)$ and $m^{*}$ of doped compounds. In order to clarify the origin for affecting $S$ in doped compounds, $m^{*}$ values were calculated using the measured $S$ and the carrier concentration $\left(n_{c}\right)$ for the whole samples. The $m^{*}$ is one of the critical factors determining $S$ and estimated with the following equation:

$$
m^{*}=\frac{h^{2}}{2 k_{B} T}\left[\frac{n_{c}}{4 \pi F_{1 / 2}(\eta)}\right]^{2 / 3},
$$

where $h, k_{B}, F_{n}$, and $\eta$ are the Planck constant, Boltzmann constant, $n$th order Fermi integral, and the reduced Fermi energy, respectively.

As shown in Figure $3, m^{*}$ was decreased by the doping compared to that of undoped compound. It should be noted that $m^{*}$ values of the interstitial $\mathrm{Cu}$ site modified

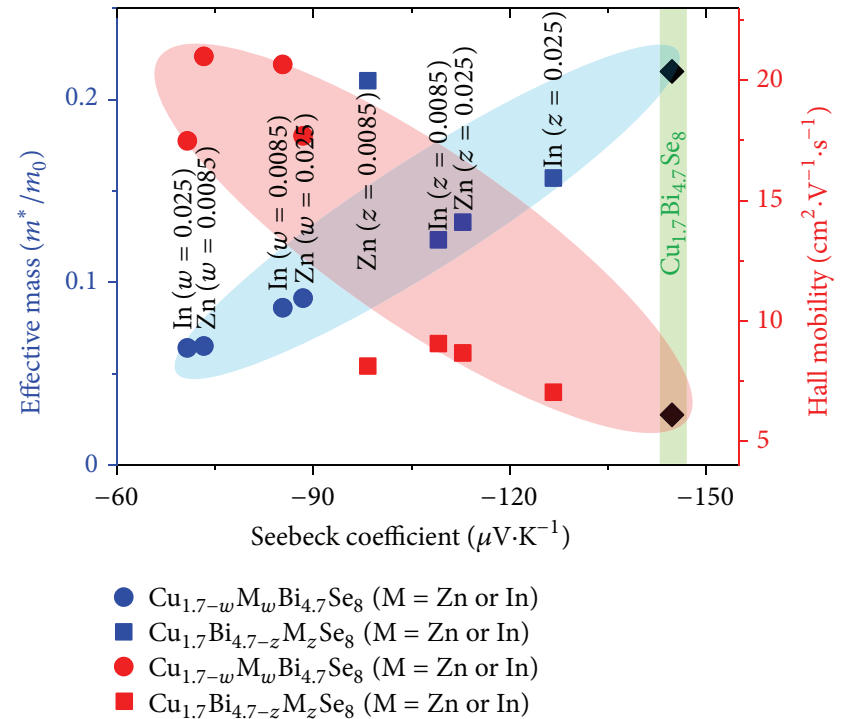

FIGURE 3: Effective mass $\left(\mathrm{m}^{*} / \mathrm{m}_{0}\right)$ and Hall mobility $\left(\mu_{H}\right)$ as functions of Seebeck coefficient $(S)$ for $\mathrm{Cu}_{1.7-w} \mathrm{M}_{w} \mathrm{Bi}_{4.7} \mathrm{Se}_{8}$ and $\mathrm{Cu}_{1.7} \mathrm{Bi}_{4.7-z} \mathrm{M}_{z} \mathrm{Se}_{8}$ with varying doping levels and dopants.

$\mathrm{Cu}_{1.7-w} \mathrm{M}_{w} \mathrm{Bi}_{4.7} \mathrm{Se}_{8}$ compounds were much lower than those of $\mathrm{Cu}_{1.7} \mathrm{Bi}_{4.7-z} \mathrm{M}_{z} \mathrm{Se}_{8}$. Furthermore, $\mu_{H}$ was inversely proportional to $\mathrm{m}^{*}$ due to the reduced mass. In principle, the reduced $m^{*}$ enables the energetic movement of charge carriers in the highly degenerate semiconductors, resulting 


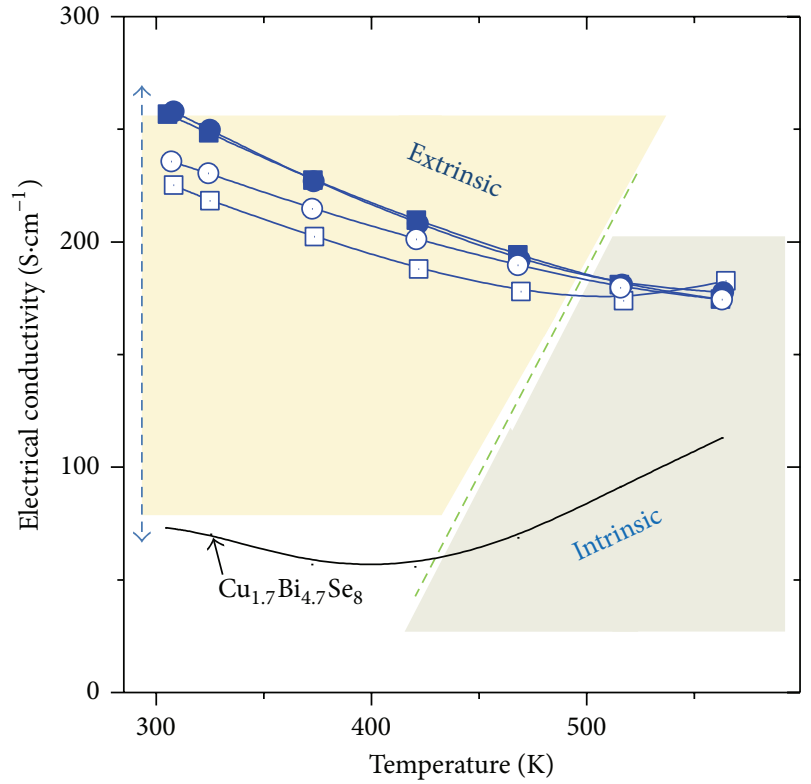

(a)

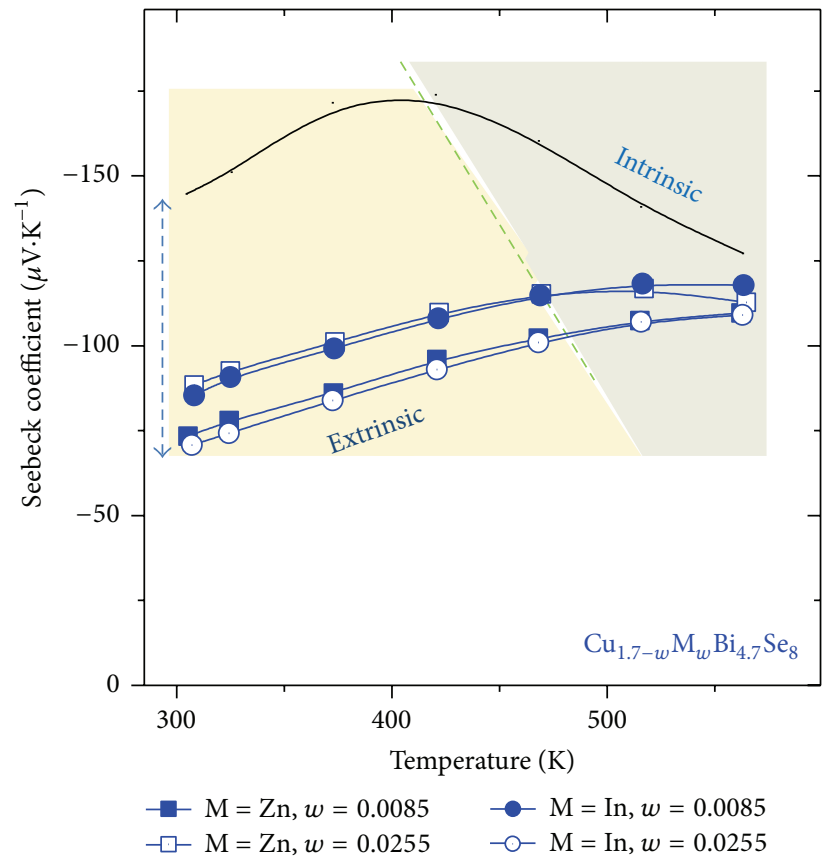

(c)

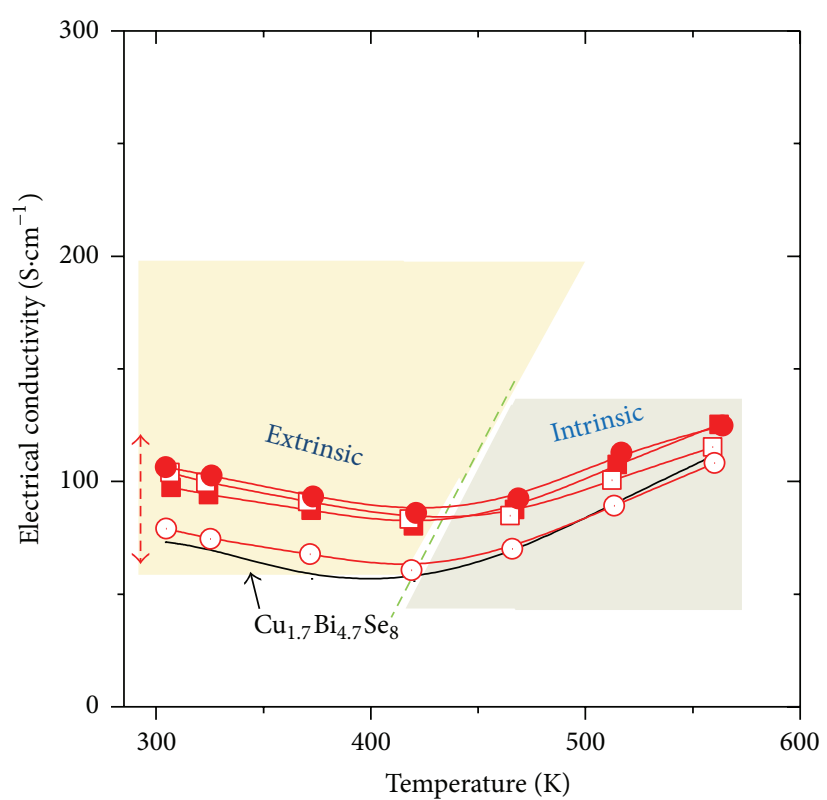

(b)

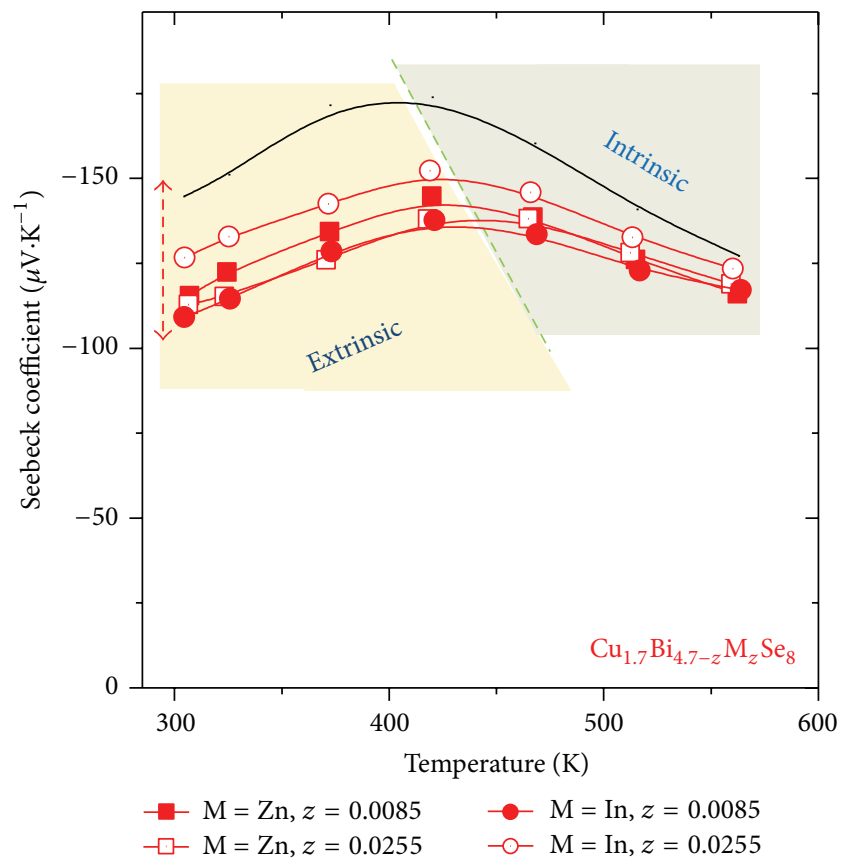

(d)

FigURE 4: Electrical conductivity $(\sigma)$ as a function of temperature for (a) $\mathrm{Cu}_{1.7-w} \mathrm{M}_{w} \mathrm{Bi}_{4.7} \mathrm{Se}_{8}$ and (b) $\mathrm{Cu}_{1.7} \mathrm{Bi}_{4.7-z} \mathrm{M}_{z} \mathrm{Se}_{8}$. Seebeck coefficient $(S)$ as a function of temperature for (c) $\mathrm{Cu}_{1.7-w} \mathrm{M}_{w} \mathrm{Bi}_{4.7} \mathrm{Se}_{8}$ and (d) $\mathrm{Cu}_{1.7} \mathrm{Bi}_{4.7-z} \mathrm{M}_{z} \mathrm{Se}_{8}$.

in the decrease of $S$. Considering the slight change of $n_{c}$ in the inset of Figure 2(b), it is concluded that the decrease in $S$ is largely affected by the reduced $m^{*}$ via the modification of interstitial $\mathrm{Cu}$ site.

In Figure 4(a), $\sigma$ of $\mathrm{Cu}_{1.7-w} \mathrm{M}_{w} \mathrm{Bi}_{4.7} \mathrm{Se}_{8}$ was drastically changed by the modification of $\mathrm{Cu}$ sites compared to that of $\mathrm{Bi}$ sites $\left(\mathrm{Cu}_{1.7} \mathrm{Bi}_{4.7-z} \mathrm{M}_{z} \mathrm{Se}_{8}\right)$. According to the theoretical calculation, interstitial $\mathrm{Cu}$ generates electron carriers in $\mathrm{Cu}_{x+y} \mathrm{Bi}_{5-y} \mathrm{Se}_{8}$ system [18]. Therefore, more electrons can be generated by the elemental doping at the interstitial $\mathrm{Cu}$ site. Indeed, higher $n_{c}, \mu_{H}$, and the smaller $m^{*}$ were observed in $\mathrm{Cu}_{1.7-w} \mathrm{M}_{w} \mathrm{Bi}_{4.7} \mathrm{Se}_{8}$ compared to those of $\mathrm{Cu}_{1.7} \mathrm{Bi}_{4.7-z} \mathrm{M}_{z} \mathrm{Se}_{8}$. In Figures 4(a) and 4(b), with increasing the doping level, the region of intrinsic conduction also shifts to higher temperatures. This is a typical behavior of a degenerate semiconductor, since the increased extrinsic majority carriers suppress the contribution of the minority carriers and hence increase the onset temperature of intrinsic conduction. 


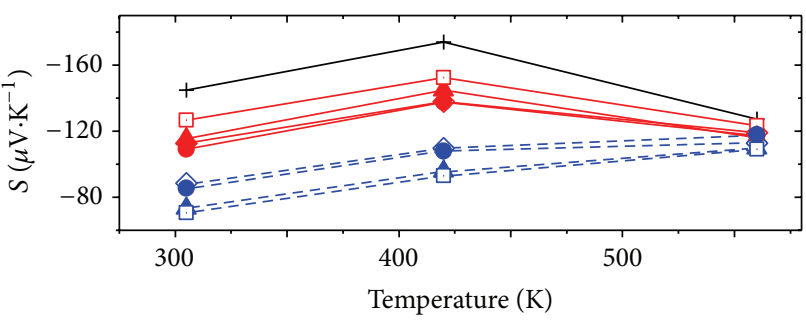

(a)

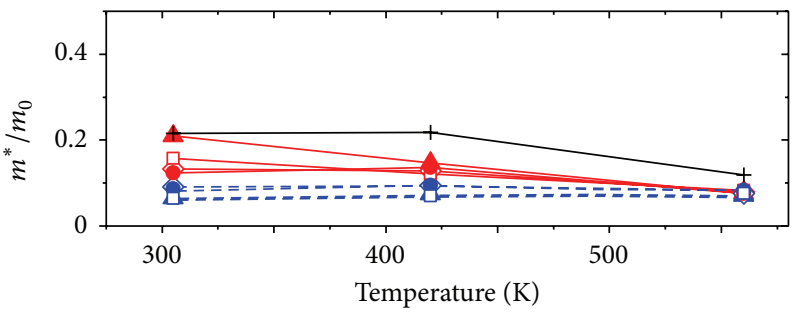$$
\begin{array}{ll}
\leftarrow \mathrm{Cu}_{1.7} \mathrm{Bi}_{4.7} \mathrm{Se}_{8} & \rightarrow-\operatorname{In}(z=0.025) \\
\diamond-\mathrm{Zn}(z=0.025) & \rightarrow-\mathrm{In}(z=0.0085) \\
\bullet-\mathrm{Zn}(z=0.0085) & -\square-\mathrm{In}(w=0.025) \\
-\diamond-\mathrm{Zn}(w=0.025) & -\bullet-\operatorname{In}(w=0.0085) \\
-\triangle-\mathrm{Zn}(w=0.0085) &
\end{array}
$$

(c)

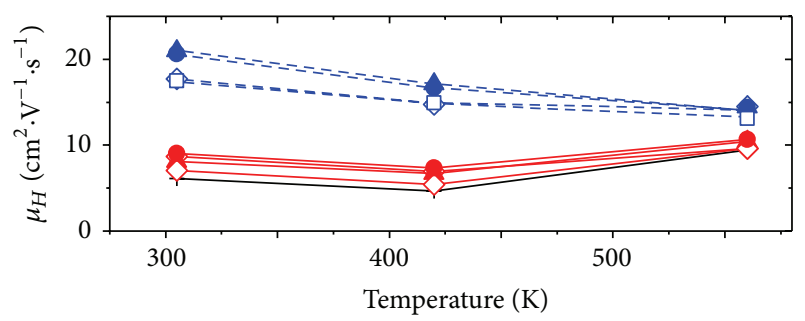

(b)

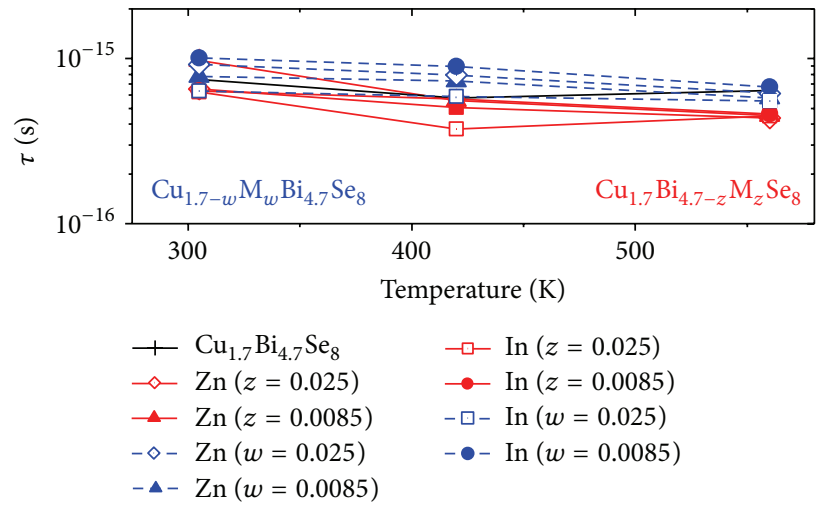

(d)

Figure 5: (a) Seebeck coefficient $(S)$, (b) Hall mobility $\left(\mu_{H}\right)$, (c) effective mass $\left(m^{*} / m_{0}\right)$, and (d) carrier relaxation time $(\tau)$ as a function of temperature for $\mathrm{Cu}_{1.7-w} \mathrm{M}_{w} \mathrm{Bi}_{4.7} \mathrm{Se}_{8}$ and $\mathrm{Cu}_{1.7} \mathrm{Bi}_{4.7-z} \mathrm{M}_{z} \mathrm{Se}_{8}$ with varying doping levels and dopants.

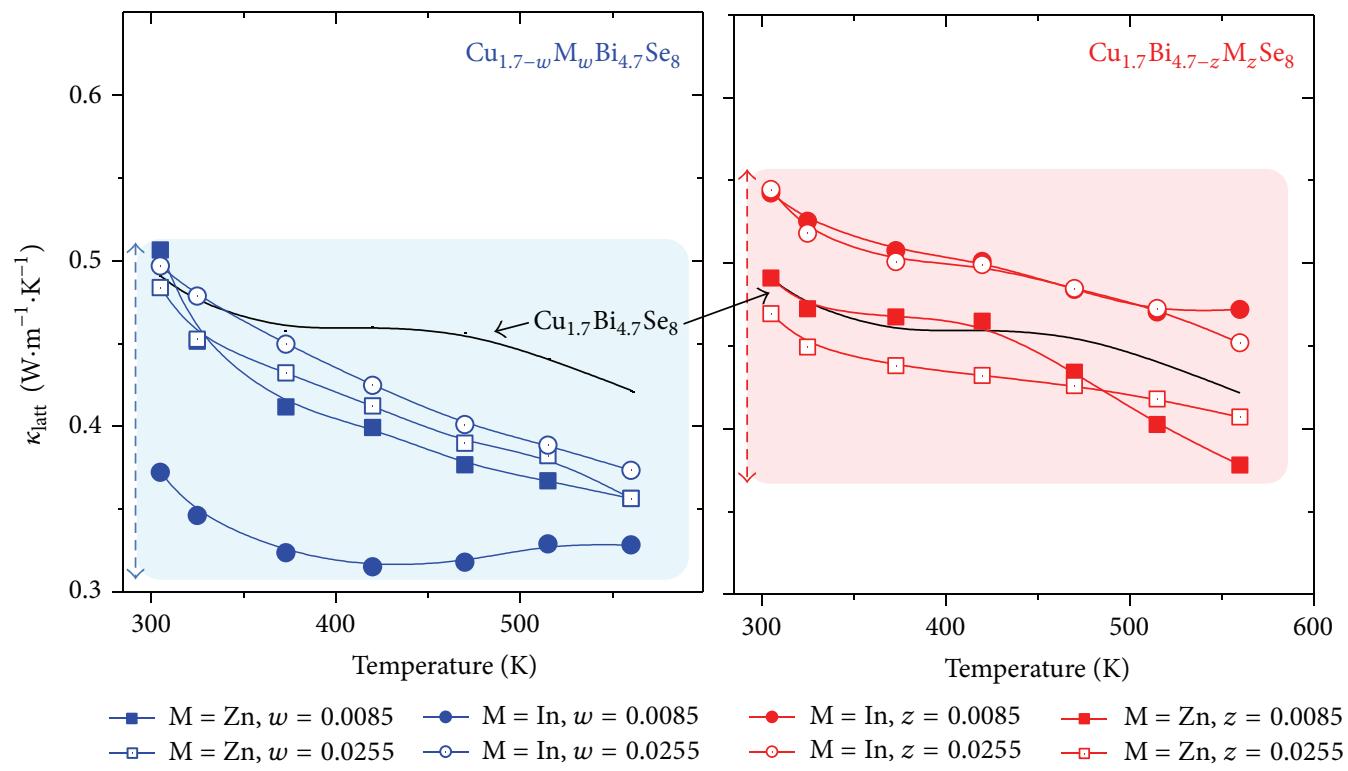

(a)

(b)

Figure 6: Lattice thermal conductivity ( $\kappa_{\text {latt }}$ ) as a function of temperature for (a) $\mathrm{Cu}_{1.7-w} \mathrm{M}_{w} \mathrm{Bi}_{4.7} \mathrm{Se}_{8}$ and (b) $\mathrm{Cu}_{1.7} \mathrm{Bi}_{4.7-z} \mathrm{M}_{z} \mathrm{Se}_{8}$ with varying doping levels and dopants.

As shown in Figures 4(c) and 4(d), negative $S$ values for all samples were observed over the entire temperature range, suggesting that the electrical conduction was dominated by $n$-type carriers. In Figure 5, it was confirmed that the change in $S$ at $560 \mathrm{~K}$ was due to the combined effect of decreased $m^{*}$ and increased $\mu_{H}$. Regardless of doping level and sites, carrier relaxation time $(\tau)$ was nearly the same (a few femtoseconds) for all samples. Figure 6 shows $\kappa_{\text {latt }}$ as a function of temperature. The value of $\kappa_{\text {latt }}$ was calculated from the relation of $\kappa=\kappa_{\text {latt }}+\kappa_{\text {elec }}$, in which $\kappa_{\text {elec }}$ is the electronic contribution. 
The value of $\kappa_{\text {elec }}$ was estimated using the Wiedemann-Franz law, $\kappa_{\text {elec }}=L \cdot T \cdot \sigma$, in which $L$ denotes the Lorenz number, taken to be $L=\left(\pi^{2} / 3\right)\left(k_{B} / e\right)^{2} \sim 2.45 \times 10^{-8} \mathrm{~V}^{2} \cdot \mathrm{K}^{-2}$. However, this value is valid for the estimation of $\kappa_{\text {latt }}$ in metals, not in heavily doped semiconductors like TE materials especially at high temperature. In semiconductors, the $L$ depends on $\eta$ and scattering factor $(r)$, which can be derived from the temperature dependence of $\mu_{H}\left(\mu_{H} \propto T^{-(3 / 2)+r}\right)$ and decreases as $\eta$ decreases with increasing temperature. The $L$ is given as

$$
\begin{aligned}
L=\left(\frac{k_{b}}{e}\right)^{2}( & \frac{(r+7 / 2) F_{r+(5 / 2)}(\eta)}{(r+3 / 2) F_{r+(1 / 2)}(\eta)} \\
& \left.-\left[\frac{(r+(5 / 2)) F_{r+(3 / 2)}(\eta)}{(r+(3 / 2)) F_{r+(1 / 2)}(\eta)}\right]^{2}\right),
\end{aligned}
$$

where $F_{n}(\eta)$ is the $n$th order Fermi integral, $F_{n}(\eta)=$ $\int_{0}^{\infty}\left(x^{n} /\left(1+e^{x-\eta}\right)\right) d x[19]$.

Calculated $L$ was nearly constant in all compounds and was in the range of $2.48-2.58 \times 10^{-8} \mathrm{~V}^{2} \cdot \mathrm{K}^{-2}$. As shown in Figure $6, \kappa_{\text {latt }}$ was much decreased by the modification of $\mathrm{Cu}$ sites compared to that of $\mathrm{Bi}$ sites. This is mainly ascribed to the mass difference between site ions $(\mathrm{Cu}$ or $\mathrm{Bi})$ and dopants. Indeed, the mass difference for interstitial $\mathrm{Cu}$ and In is 114.82 compared to 29.2 for the substitutional $\mathrm{Bi}$ and In. The values of $\kappa$, ranging from $0.47 \mathrm{~W} \cdot \mathrm{m}^{-1} \cdot \mathrm{K}^{-1}$ to $0.69 \mathrm{~W} \cdot \mathrm{m}^{-1} \cdot \mathrm{K}^{-1}$, were found for all compounds, and $\kappa$ showed a weak temperature dependence. These $\kappa$ values are much lower than those of state-of-the-art low $\kappa_{\text {latt }}$ systems, such as $\mathrm{Zn}_{4} \mathrm{Sb}_{3}(\kappa \sim$ $1.05 \mathrm{~W} \cdot \mathrm{m}^{-1} \cdot \mathrm{K}^{-1}$ at $\left.300 \mathrm{~K}\right)[20]$ and $\mathrm{Cu}_{2-x} \mathrm{Se}\left(\kappa \sim 1 \mathrm{~W} \cdot \mathrm{m}^{-1} \cdot \mathrm{K}^{-1}\right.$ at $400 \mathrm{~K})$ [21]. We suggest that the reason of the extremely low $\kappa$ values in this system is due to the strong phonon scattering and the short phonon mean free path of below $1 \mathrm{~nm}$, which is much shorter than the size of unit cell of this structure. The strong phonon scattering is mainly attributed to the structural complexities based on the combined effect of point defects and intrinsic disorders. The maximum ZT values achieved in this study for $\mathrm{Cu}$ site and $\mathrm{Bi}$ site modified $\mathrm{Cu}_{1.6915} \mathrm{In}_{0.0085} \mathrm{Bi}_{4.7} \mathrm{Se}_{8}$ and $\mathrm{Cu}_{1.7} \mathrm{Bi}_{4.6915} \mathrm{Zn}_{0.0085} \mathrm{Se}_{8}$ were 0.25 and 0.18 at $560 \mathrm{~K}$, respectively. It is expected from the low $\sigma$ values of $\mathrm{Cu}-\mathrm{Bi}-\mathrm{Se}$ system that the present TE properties can be much enhanced by optimizing PF through tuning $n_{c}$. The modification of $\mathrm{Cu}$ site is an effective way to reduce $\kappa_{\text {latt }}$ compared to that of $\mathrm{Bi}$ site. It is worth noting that intrinsically low $\kappa$ of this material is less sensitive to temperature gradient because of the complex mixture of extraordinary structural disorders. There is still remaining a possibility for the further improvement of TE performance by the optimization of resonant level doping to enhance $\mathrm{PF}$ without sacrificing $\kappa$.

\section{Conclusions}

The electronic and thermal transport properties of $\mathrm{Cu}_{1.7} \mathrm{Bi}_{4.7} \mathrm{Se}_{8}$ pavonite homologues $(\mathrm{N}=3)$ with monoclinic $\mathrm{C} 2 / \mathrm{m}$ space group were investigated in the view point of the correlation with complex crystal structure via the modification of $\mathrm{Cu}$ or Bi sites with dopants. $\sigma$ and $\kappa_{\text {latt }}$ were much affected by the modification of $\mathrm{Cu}$ sites compared to that of $\mathrm{Bi}$ sites. This is due to the origin of $n$-type conduction and the intrinsically low $\kappa_{\text {latt }}$, which is highly related to the structural configuration of the interstitial $\mathrm{Cu}$ sites in this system. Though the $\mathrm{Cu}_{1.7} \mathrm{Bi}_{4.7} \mathrm{Se}_{8}$ compound showed an extremely low $\kappa_{\text {latt }}$, additional $\sim 30 \%$ reduction in $\kappa_{\text {latt }}$ was achieved by the modification of $\mathrm{Cu}$ sites. Therefore, we anticipate that the further fine-tuning of the electronic and thermal properties based on the correlated findings about structural modifications gives a possible enhancement of TE performance in the $\mathrm{Cu}-\mathrm{Bi}-\mathrm{Se}$ system.

\section{Acknowledgments}

This research was supported by the Institute for Basic Science (IBS) in Korea and by the Human Resources Development Program (no. 20124010203270) of the Korea Institute of Energy Technology Evaluation and Planning (KETEP) grant funded by the Korea government Ministry of Trade, Industry and Energy.

\section{References}

[1] F. J. Disalvo, "Thermoelectric cooling and power generation," Science, vol. 285, no. 5428, pp. 703-706, 1999.

[2] G. J. Snyder and E. S. Toberer, "Complex thermoelectric materials," Nature Materials, vol. 7, no. 2, pp. 105-114, 2008.

[3] H. J. Goldsmid, "Recent studies of bismuth telluride and its alloys," Journal of Applied Physics, vol. 32, no. 10, pp. 2198-2202, 1961.

[4] B. Abeles, "Lattice thermal conductivity of disordered semiconductor alloys at high temperatures," Physical Review, vol.131, no. 5, pp. 1906-1911, 1963.

[5] W. M. Yim, E. V. Fitzke, and F. D. Rosi, "Thermoelectric properties of $\mathrm{Bi}_{2} \mathrm{Te}_{3}-\mathrm{Sb}_{2} \mathrm{Te}_{3}-\mathrm{Sb}_{2} \mathrm{Se}_{3}$ pseudo-ternary alloys in the temperature range 77 to $300 \mathrm{~K}$," Journal of Materials Science, vol. 1, no. 1, pp. 52-65, 1966.

[6] C. Wood, "Materials for thermoelectric energy conversion," Reports on Progress in Physics, vol. 51, no. 4, pp. 459-539, 1988.

[7] B. Wölfing, C. Kloc, J. Teubner, and E. Bucher, "High performance thermoelectric $\mathrm{Tl}_{9} \mathrm{BiTe}_{6}$ with an extremely low thermal conductivity," Physical Review Letters, vol. 86, no. 19, pp. 43504353, 2001.

[8] K. Kurosaki, A. Kosuga, H. Muta, M. Uno, and S. Yamanaka, " $\mathrm{Ag}_{9} \mathrm{TlTe}_{5}$ : a high-performance thermoelectric bulk material with extremely low thermal conductivity," Applied Physics Letters, vol. 87, no. 6, Article ID 061919, 2005.

[9] B. C. Sales, D. Mandrus, and R. K. Williams, "Filled skutterudite antimonides: a new class of thermoelectric materials," Science, vol. 272, no. 5266, pp. 1325-1328, 1996.

[10] V. Keppens, D. Mandrus, B. C. Sales et al., "Localized vibrational modes in metallic solids," Nature, vol. 395 , no. 6705, pp. 876878, 1998.

[11] J. Yang, W. Zhang, S. Q. Bai, Z. Mei, and L. D. Chen, "Dualfrequency resonant phonon scattering in $\mathrm{Ba}_{x} \mathrm{R}_{y} \mathrm{Co}_{4} \mathrm{Sb}_{12}(R=$ La, Ce, and Sr)," Applied Physics Letters, vol. 90, no. 19, Article ID 192111, 2007.

[12] J. L. Cohn, G. S. Nolas, V. Fessatidis, T. H. Metcalf, and G. A. Slack, "Glasslike heat conduction in high-mobility crystalline 
semiconductors," Physical Review Letters, vol. 82, no. 4, pp. 779782, 1999.

[13] D.-Y. Chung, T. Hogan, P. Brazis et al., " $\mathrm{CsBi}_{4} \mathrm{Te}_{6}$ : a highperformance thermoelectric material for low- temperature applications," Science, vol. 287, no. 5455, pp. 1024-1027, 2000.

[14] O. Delaire, J. Ma, K. Marty et al., "Giant anharmonic phonon scattering in PbTe," Nature Materials, vol. 10, no. 8, pp. 614-619, 2011.

[15] W. Xie, X. Tang, Y. Yan, Q. Zhang, and T. M. Tritt, "Unique nanostructures and enhanced thermoelectric performance of melt-spun BiSbTe alloys," Applied Physics Letters, vol. 94, no. 10, Article ID 102111, 2009.

[16] W. K. Liebmann and E. A. Miller, "Preparation phase-boundary energies, and thermoelectric properties of Insb-Sb eutectic alloys with ordered microstructures," Journal of Applied Physics, vol. 34, no. 9, pp. 2653-2659, 1963.

[17] A. I. Hochbaum, R. Chen, R. D. Delgado et al., "Enhanced thermoelectric performance of rough silicon nanowires," Nature, vol. 451, no. 7175, pp. 163-167, 2008.

[18] J. Y. Cho, H. Mun, B. Ryu et al., "Cu-Bi-Se-based pavonite homologue: a promising thermoelectric material with low lattice thermal conductivity," Journal of Material Chemistry A, vol. 1, no. 34, pp. 9768-9774, 2013.

[19] L. D. Zhao, S. Hao, S. H. Lo et al., "High thermoelectric performance via hierarchical compositionally alloyed nanostructures," Journal of the American Chemical Society, vol. 135, no. 19, pp. 7364-7370, 2013.

[20] G. J. Snyder, M. Christensen, E. Nishibori, T. Caillat, and B. B. Iversen, "Disordered zinc in $\mathrm{Zn}_{4} \mathrm{Sb}_{3}$ with phonon-glass and electron-crystal thermoelectric properties," Nature Materials, vol. 3, no. 7, pp. 458-463, 2004.

[21] H. Liu, X. Shi, F. Xu et al., "Copper ion liquid-like thermoelectrics," Nature Materials, vol. 11, no. 5, pp. 422-425, 2012. 

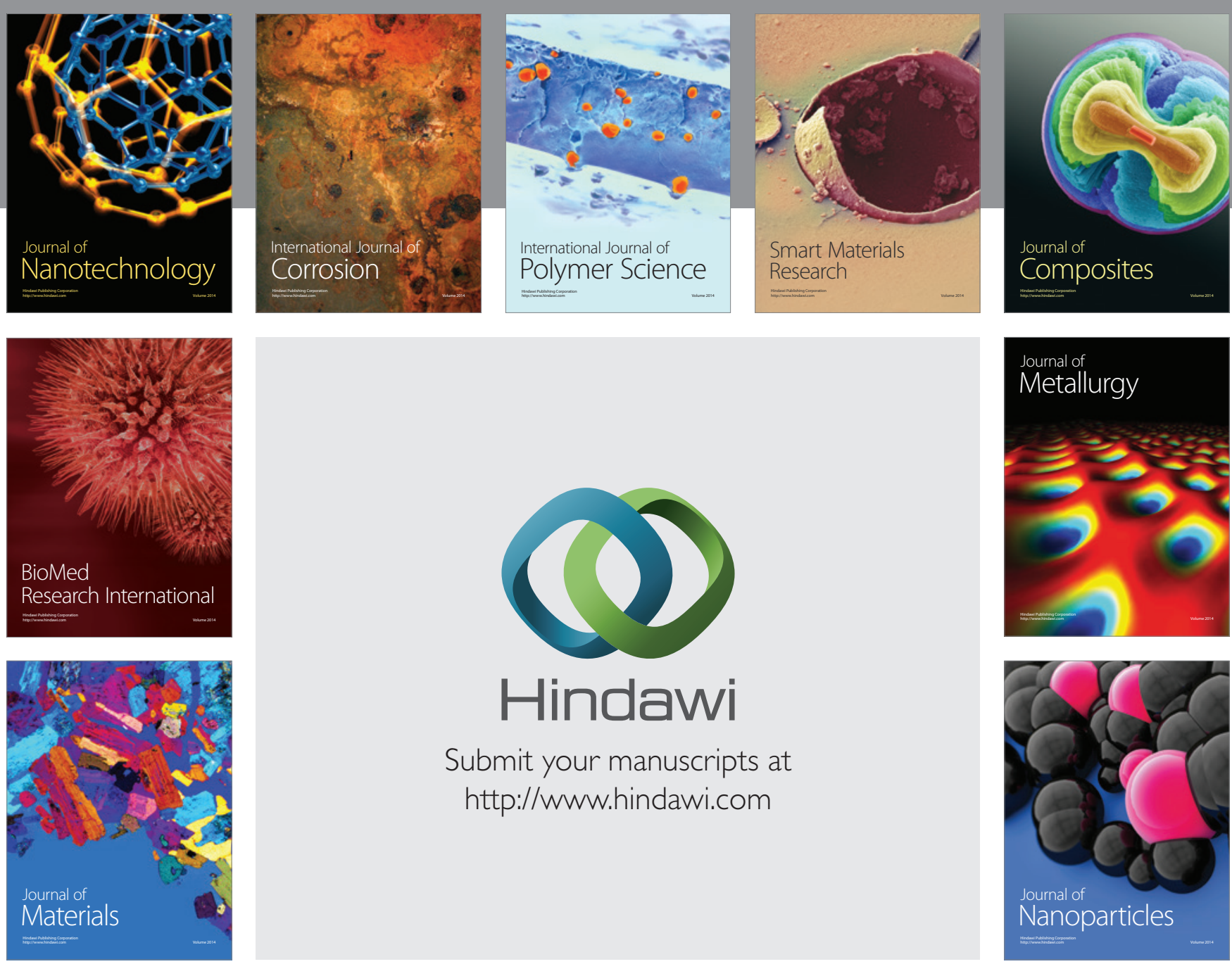

Submit your manuscripts at http://www.hindawi.com
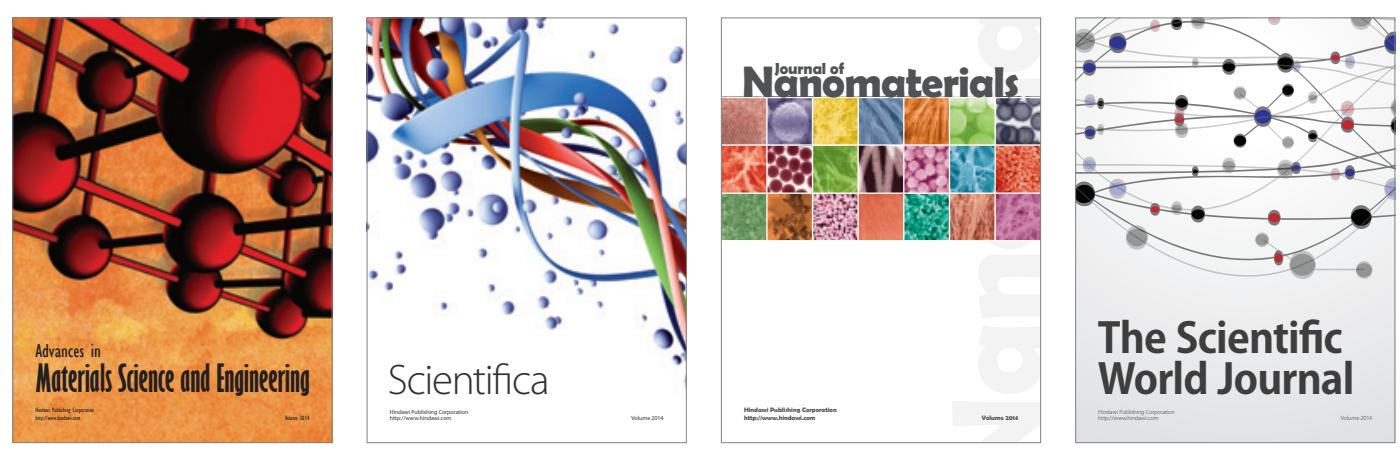

\section{The Scientific World Journal}
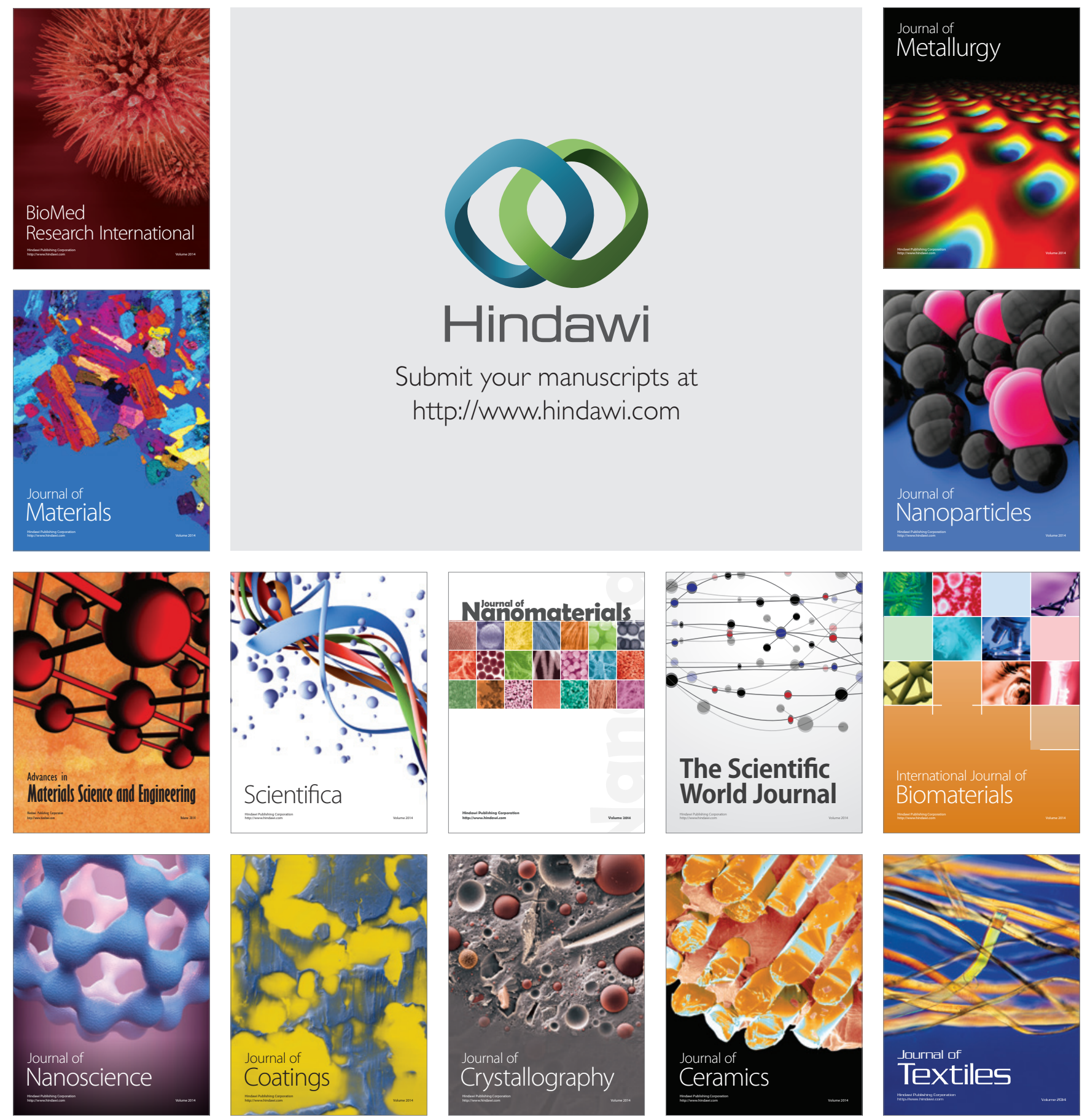